\title{
DETERMINAÇÃO DE INCREMENTO DE ALTURA DE CAMALHÃO NA INTEGRAÇÃO TERRAÇO-ESTRADA ${ }^{1}$
}

\author{
Max Well de Oliveira Rabelo ${ }^{2}$, Nori Paulo Griebeler ${ }^{2}$
}

\section{ABSTRACT \\ RIDGE HEIGHT INCREASE \\ DETERMINATION IN TERRACE-ROAD INTEGRATION}

Hydric erosion is one of the major causes of agricultural land degradation, resulting in economic, social, and environmental losses. Conservation practices are important tools to reduce erosion risks and their correct design is fundamental to success. Models for designing both rural roads and terraces systems are currently used, however, their integration is not available. The integration of terracing systems and runoff coming from roads, although recommended and utilized, can increase erosion risk and terraces disruption, without a proper dimensioning practice. So, this study aimed to develop a terrace-road integration model and a calculation routine that allows this integration. The routine was used for sizing an integrated conservation system. The results show that although in some terraces the increase in height is small, dimensioning is necessary, because it allows to identify the critical points of integration, and, without it, the terrace would go through storage problems. It was concluded that the methodology presented made possible to calculate the increase in the recommended height for terraces, as a viable alternative, with a small increase in the terrace height. The calculation routine application was simple, but the development of computational tools would facilitate its use and reduce miscalculation risks.

KEY-WORDS: Hydrological model; soil conservation; erosion.

\section{INTRODUÇÃO}

O escoamento superficial, ao carrear partículas de solo, leva, consigo, grande quantidade de defensivos agrícolas, sementes, nutrientes e matéria orgânica, causando grandes danos ao homem e ao ambiente. Segundo Pruski et al. (2006), a erosão reduz a capacidade produtiva dos solos, resultando em aumento dos custos de produção e diminuição dos lucros dos agricultores, levando, em alguns casos, à total degradação de áreas agrícolas.

\section{RESUMO}

A erosão hídrica é um dos principais causadores de degradação em áreas agrícolas, resultando em prejuízos econômicos, sociais e ambientais. As práticas conservacionistas são ferramentas importantes para reduzir o risco de erosão e o seu correto dimensionamento é fundamental para o sucesso. Atualmente, existem tanto modelos para o dimensionamento de estradas rurais quanto para o dimensionamento de terraços, porém, não há integração entre eles. A integração entre terraceamento e acumulação de escoamento superficial de estradas, embora recomendada e utilizada, pode aumentar os riscos de erosão e rompimento dos terraços, caso não seja realizada com o correto dimensionamento. Neste sentido, o presente trabalho teve por objetivo desenvolver um modelo de integração terraço-estrada e uma rotina de cálculo para permitir tal integração. A rotina foi utilizada para dimensionar um sistema conservacionista integrado. Os resultados obtidos mostram que, embora, em alguns terraços, o incremento na altura seja pequeno, o dimensionamento se faz necessário, pois permite identificar pontos críticos à integração, e, sem ele, o terraço teria problemas de armazenamento. Concluiu-se que a metodologia apresentada permitiu calcular o incremento na altura recomendada dos terraços, sendo esta uma alternativa viável, com um pequeno incremento na altura do terraço. A aplicação da rotina de cálculo foi simples, porém, a geração de ferramentas computacionais facilitaria o seu uso e reduziria os riscos de erro de cálculo.

PALAVRAS-CHAVE: Modelo hidrológico; conservação do solo; erosão.

No ambiente rural, além das áreas agricultáveis, as estradas não pavimentadas também são atingidas pela erosão, bem como são potencializadoras deste problema, caso não sejam tomadas medidas adequadas de controle. Muitas vezes, a erosão chega a inviabilizar o tráfego, dificultando o acesso da população rural aos centros urbanos, podendo, também, prejudicar o escoamento da produção agrícola e, inclusive, gerar aumento no custo de produção e redução da rentabilidade das atividades rurais. De acordo com Oliveira (2010), estes fatores 
estimulam o êxodo, gerando problemas sociais nos centros urbanos, como desemprego e marginalização da população.

A redução dos problemas de erosão em estradas de terra pode ser obtida por meio da adoção de medidas que evitem que a água proveniente do escoamento superficial, tanto aquele gerado na própria estrada como o proveniente das áreas às suas margens, se acumule na estrada e passe a utilizá-la para o seu escoamento (Griebeler 2002). Uma destas medidas consiste em coletar, nas laterais da estrada, a água escoada pela mesma e encaminhá-la, de modo a não provocar erosão, para escoadouros naturais, artificiais, bacias de acumulação e infiltração ou outro sistema de retenção localizado no terreno marginal.

A construção de estruturas específicas para a acumulação e infiltração da água advinda das estradas é uma alternativa usual e eficiente, porém, Griebeler (2002) cita um sistema bastante comum e prático, no qual é possível a integração entre o sistema de terraceamento agrícola e a estrada. Esta integração, no entanto, pode ser uma das causas do rompimento de terraços, em virtude do excedente de escoamento superficial. Nestes casos, o dimensionamento dos terraços deverá ser realizado prevendo o acréscimo de escoamento advindo do leito das estradas e carreadores.

A integração entre terraço e estrada também reduz a área destinada à implantação das estruturas para acumulação e implantação, uma vez que, na implantação das bacias, a área "perdida" para a construção de tais estruturas, muitas vezes, desestimula o produtor rural a implantá-las, principalmente em propriedades de atividade agrícola nas quais estas obras dificultam a movimentação de máquinas e operações como o plantio. Assim, a integração terraço-estrada também aumenta a viabilidade da implantação de práticas conservacionistas e a adoção destas, por parte dos produtores rurais.

Para o cálculo do espaçamento entre desaguadouros em estradas e do volume a ser armazenado nas bacias, Griebeler et al. (2005) desenvolveram um modelo que utiliza dados de precipitação baseados na equação de chuvas intensas e características geométricas das estradas e de seus canais, bem como informações de relevo e características físico-hídricas dos solos. A partir deste modelo, foi produzido o software Estradas, parte do conjunto de aplicativos de dimensionamento de sistemas hidroagrícolas HIDROS (Pruski et al. 2006), no qual encontra-se disponibilizado, também, o software Terraço, para dimensionamento e locação de sistemas de terraceamento.

Estes modelos e softwares, no entanto, não preveem a integração entre os terraços e as estradas. Neste sentido, o presente trabalho teve como objetivo gerar um modelo que possibilite calcular o incremento na altura necessária aos terraços, de modo que estes possam armazenar tanto o escoamento superficial da área agrícola como o das estradas rurais adjacentes, além de criar uma rotina de cálculo para determinar o incremento na altura do terraço, para a integração terraço-estrada.

\section{MATERIAL E MÉTODOS}

Para a obtenção dos dados e produção do layout de campo, o projeto foi implantado em uma área de 5,75 ha, cujo solo foi classificado como Latossolo Vermelho, com relevo suave-ondulado, localizada no campus experimental da Escola de Agronomia e Engenharia de Alimentos da Universidade Federal de Goiás, em Goiânia (GO), em 2010.

$\mathrm{O}$ trabalho foi dividido em três etapas. Inicialmente, foram coletados os dados de campo e dimensionados os terraços. Em seguida, foram locadas as estradas e coletadas as informações para o dimensionamento destas. Com os dados das estradas dimensionadas, verificou-se qual seria o incremento necessário na altura de camalhão, para viabilizar a integração terraço-estrada.

Para o dimensionamento dos terraços, foi feito levantamento altimétrico da área, com o uso de receptor Geodésico L1, operando no modo Stop and Go, com tempo de coleta de cada ponto de um minuto e densidade de 100 pontos por hectare (ABNT 1994). Os dados foram processados com o auxílio do software GNSS Solutions e interpolados no software ArcGIS, gerando um arquivo de elevação raster com resolução espacial de um metro. Foram, também, coletadas informações sobre o uso e manejo do solo e, para determinação da taxa de infiltração, foi realizado teste com infiltrômetro de anéis concêntricos (Costa et al. 1999).

A partir da imagem de elevação obtida por meio do ArcGIS, foi gerada a imagem de declividade, no Módulo Locação do software Terraço 4.0, e, com os dados coletados em campo, foi gerado um arquivo vetorial, com a localização de cada terraço, além de um relatório com as informações resultantes do dimensionamento. 
Uma vez dimensionados os terraços, e com o arquivo contendo a localização de cada um deles, em software CAD, foram locadas as estradas, as quais foram subdivididas em trechos localizados entre cada terraço. No CAD, foi coletado o comprimento da estrada e, a partir do relatório do Terraço 4.0, obteve-se o espaçamento vertical de cada trecho de estrada, sendo possível, então, calcular a declividade do leito da estrada.

Posteriormente, procedeu-se, com o auxílio do software Estradas 2.0, ao cálculo do espaçamento entre desaguadouros da estrada, a fim de verificar se o espaçamento entre os terraços era adequado para ser utilizado como distância entre desaguadouros da estrada. Para tal, foram considerados como parâmetros da estrada uma largura de 4 metros, declividade transversal de $3 \%$, infiltração no leito da estrada de $1 \mathrm{~mm} \mathrm{~h}^{-1}$, tensão crítica de cisalhamento de 2,03 Pa, densidade do solo de $1,4 \mathrm{~g} \mathrm{~cm}^{-3}$ e erodibilidade de $0,0036 \mathrm{~g} \mathrm{~cm}^{-2} \mathrm{~min}^{-1} \mathrm{~Pa}^{-1}$, parâmetros obtidos por Oliveira et al. (2009), em trabalhos realizados no mesmo campo experimental. Foi, também, utilizada a equação de chuvas intensas para a localidade de Goiânia, determinada por Oliveira et al. (2005). Caso existissem áreas de contribuição externa de escoamento superficial à estrada, estas seriam registradas no software, onde seriam informados o comprimento de rampa e a taxa de infiltração estável desta área. $\mathrm{Na}$ área experimental, entretanto, não foi verificada nenhuma ocorrência de contribuição externa.

Verificada a possibilidade de uso do terraço como desaguadouro para as águas da estrada, ainda no software Estradas 2.0, foi calculado o volume de escoamento superficial gerado para um comprimento de estrada correspondente ao localizado entre cada terraço. Uma vez obtido o volume de escoamento superficial da estrada a ser armazenado, foi gerada uma rotina de cálculo para a integração terraço-estrada, na qual se obteve o incremento na altura de cada terraço, para que este pudesse armazenar o excedente de volume de escoamento proveniente da estrada. Em situações em que um terraço armazenava o volume de mais de uma estrada, considerou-se a soma dos volumes de escoamento correspondentes a cada trecho de estrada.

A equação foi obtida a partir da equação de cálculo da altura recomendada de terraços (Pruski et al. 2006), em função do escoamento superficial a ser armazenado pelo mesmo, e, a partir de semelhança de triângulos, obteve-se a altura final recomendada para armazenamento do volume de escoamento superficial da área agrícola e do proveniente das estradas.

Este volume de escoamento superficial da estrada corresponde ao resultado da multiplicação do comprimento do terraço por uma área de seção transversal, representada por um trapézio, no qual a base menor corresponde à largura da lâmina d'água no armazenamento máximo do terraço e as laterais ao prolongamento da parede do terraço e ao terreno inclinado localizado acima do mesmo (Figura 1).

A partir da Figura 1, foi possível deduzir que a área da secção transversal do terraço final corresponde à soma da área de armazenamento do terraço inicial com a área de armazenamento do volume de escoamento proveniente da estrada, segundo a seguinte equação:

$$
A f=A i+A i n
$$

em que $A f=$ Área final $\left(\mathrm{m}^{2}\right) ; A i=$ Área inicial $\left(\mathrm{m}^{2}\right)$; e Ain = Área de incremento $\left(\mathrm{m}^{2}\right)$. Logo, cada uma das áreas pôde ser calculada pelas seguintes equações:

$$
A f=\frac{H \cdot L}{2} \text { e } A i=\frac{h \cdot l}{2}
$$

em que $H=$ altura do terraço final (m); $L=$ largura da lâmina d'água do terraço final $(\mathrm{m}) ; h=$ altura do terraço inicial (m); e $l=$ largura da lâmina d'água do terraço inicial $(\mathrm{m})$.

Reordenando a equação 1 , em função da área de incremento, e substituindo-se $A f$ e $A i$, tem-se a equação 3 :

$$
\text { Ain }=\frac{\text { H. L }}{2}-\frac{\text { h.l }}{2}
$$

$\mathrm{Na}$ equação 4, o denominador das frações passa a multiplicar Ain:

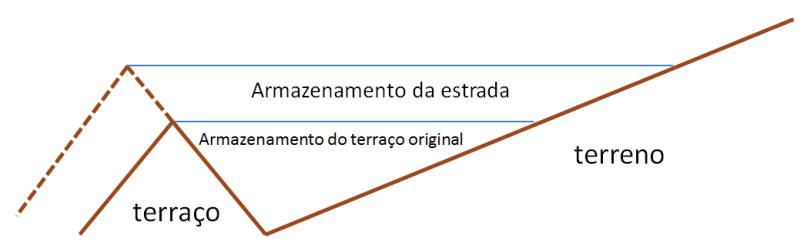

Figura 1. Esquema do aumento da área de armazenamento do terraço, em função do armazenamento do escoamento superficial da estrada. 


$$
\text { 2Ain }=\text { H. L }- \text { h.l }
$$

Finalmente, na equação 5 , tem-se a fórmula para o cálculo de $H$ :

$$
\mathrm{H}=\frac{2 \mathrm{Ain}+\mathrm{h} \cdot \mathrm{l}}{\mathrm{L}}
$$

A área de secção transversal de um terraço pode ser calculada pela área do triângulo de altura $H$ e largura de lâmina d'água $L$. A largura de lâmina d'água pode, ainda, ser dividida em largura correspondente à inclinação da parede do terraço $(\mathrm{Lm})$ e largura correspondente à inclinação do terreno $(L t)$ (Figura 2), como ilustrado nas equações 13, 14, 15 e 16, obtidas a partir dos cálculos demonstrados nas equações 6 a 11:

$$
\begin{aligned}
& L=L m+L t \\
& S m=\frac{H}{L m} \\
& L m=\frac{H}{S m} \\
& S t=\frac{H}{L t} \\
& L t=\frac{H}{S t} \\
& L=\frac{H}{S m}+\frac{H}{S t} \\
& L=H\left(\frac{S t+S m}{S m \cdot S t}\right) \\
& \text { Se } D=\left(\frac{S t+S m}{S m \cdot S t}\right)
\end{aligned}
$$

então $L=H \cdot D$

$$
\text { e } l=h . D
$$

em que $S t=$ Inclinação do terreno $(\mathrm{m} / \mathrm{m}) ; S m=$ Inclinação da parede do terraço $(\mathrm{m} / \mathrm{m}) ; \mathrm{lm}=$ largura de lâmina d'água correspondente à inclinação da parede

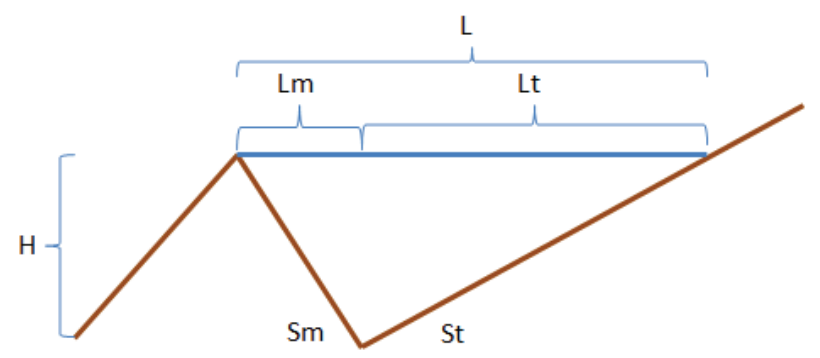

Figura 2. Subdivisão da largura de lâmina d'água do terraço em largura correspondente à inclinação da parede do terraço $(\mathrm{Lm})$ e largura correspondente à inclinação do terreno $(L t)$.

do terraço (m); e $l t=$ largura de lâmina d'água correspondente à inclinação do terreno $(\mathrm{m})$.

Substituindo-se, na equação 5 , os itens das equações 14 e 15, por meio das equações $16,17,18$ e 19 , obtemos a equação 20 :

$$
\begin{aligned}
& H=\frac{2 \operatorname{Ain}+h \cdot(h \cdot D)}{(H \cdot D)} \\
& H^{2}=\frac{2 A i n+h^{2} \cdot D}{D} \\
& H^{2}=\frac{2 A i n}{D}+h^{2} \\
& H^{2}=2 \operatorname{Ain} \cdot \frac{1}{D}+h^{2} \\
& H=\sqrt{2 \operatorname{Ain} \cdot\left(\frac{S m \cdot S t}{S m+S t}\right)+h^{2}}
\end{aligned}
$$

Como a área de secção corresponde à divisão do volume armazenado pelo comprimento do terraço, finalmente, chega-se à equação 21 :

$$
H=\sqrt{2 \frac{V}{C} \cdot\left(\frac{S m \cdot S t}{S m+S t}\right)+h^{2}}
$$

em que $H=$ Altura final do terraço (m); $V=$ Volume de escoamento superficial da estrada a ser armazenado no terraço $\left(\mathrm{m}^{3}\right) ; C=$ Comprimento do terraço que armazenará o escoamento superficial da estrada (m); $S t=$ Inclinação do terreno (m/m); Sm = Inclinação da 
parede do terraço $(\mathrm{m} / \mathrm{m})$; e $h=$ Altura do projeto inicial do terraço, sem considerar o incremento do armazenamento do escoamento superficial da estrada (m).

Desse modo, o terraço a ser construído poderá armazenar, com segurança, o volume do escoamento superficial da estrada, podendo, ainda, ser feito cálculo da altura recomendada, considerando-se o coeficiente de desuniformidade, conforme propuseram Griebeler et al. (1998). O fluxograma da execução do trabalho pode ser observado na Figura 3.

\section{RESULTADOS E DISCUSSÃO}

No total, foram gerados sete terraços, cujas especificações, como comprimento, altura recomen-

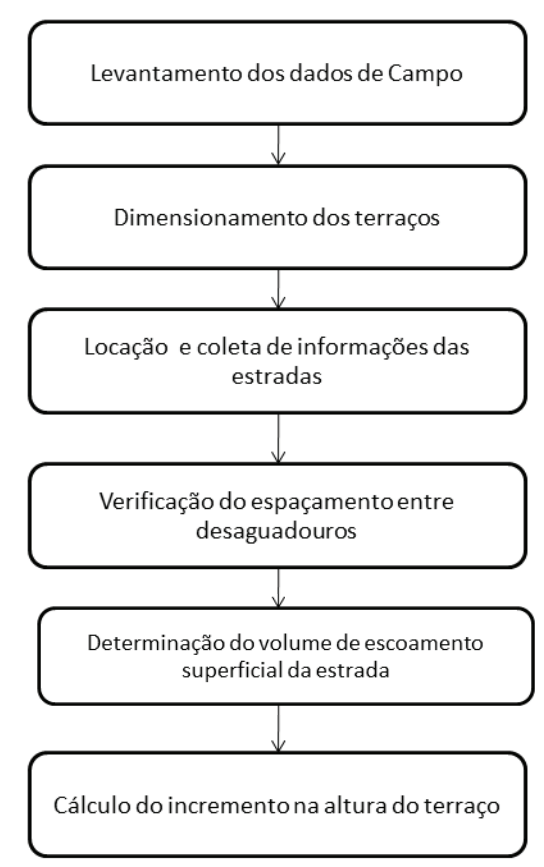

Figura 3. Fluxograma do cálculo de incremento na altura do terraço, para a integração terraço-estrada. dada e espaçamento vertical, podem ser observadas na Tabela 1. O módulo locação gerou um arquivo de vetor, que permite conhecer a localização espacial de cada terraço.

Após o dimensionamento e o conhecimento da localização de cada terraço, foram criadas duas estradas, a serem dimensionadas. Cada estrada foi subdividida em trechos localizados entre cada terraço e cada trecho recebeu uma denominação. Deste modo, foram dimensionados os trechos $1 \mathrm{~A}, 1 \mathrm{~B}, 1 \mathrm{C}$, $1 \mathrm{D}, 1 \mathrm{E}, 1 \mathrm{~F}, 1 \mathrm{G}, 2 \mathrm{~A}, 2 \mathrm{~B}, 2 \mathrm{C}, 2 \mathrm{D}$ e $2 \mathrm{E}$. Os terraços dimensionados e os trechos de estrada locados podem ser visualizados na Figura 4.

Cada trecho de estrada foi simulado separadamente, com o auxílio do software Estradas 2.0, e, como resultado do dimensionamento, a tela do software apresentou, para cada metro da estrada

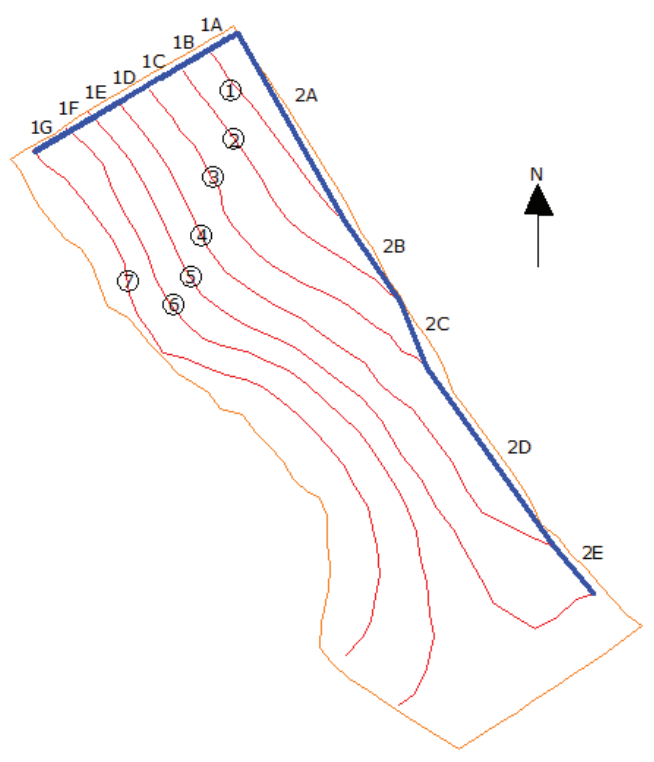

Figura 4. Área experimental, com os terraços (vermelho) e estradas (azul).

Tabela 1. Especificações dos terraços dimensionados, em área de Latossolo Vermelho, na área experimental da Escola de Agronomia e Engenharia de Alimentos da Universidade Federal de Goiás (Goiânia, GO, 2010).

\begin{tabular}{|c|c|c|c|c|c|c|}
\hline \multirow{2}{*}{ Terraço } & Cota & EV & $\mathrm{DM}$ & CT & AT & AI \\
\hline & & & $-\mathrm{m}$ & & & $\mathrm{m}^{2}$ \\
\hline 1 & 708,095 & 1,50 & 7,27 & 128,45 & 0,298 & $1.368,84$ \\
\hline 2 & 706,667 & 1,43 & 6,72 & 184,98 & 0,343 & $3.155,08$ \\
\hline 3 & 705,132 & 1,54 & 7,58 & 252,34 & 0,353 & $4.280,91$ \\
\hline 4 & 703,553 & 1,58 & 7,97 & 366,19 & 0,359 & $6.256,29$ \\
\hline 5 & 702,036 & 1,52 & 7,43 & 439,17 & 0,355 & $7.674,63$ \\
\hline 6 & 700,761 & 1,28 & 5,47 & 421,70 & 0,379 & $11.181,45$ \\
\hline 7 & 699,275 & 1,48 & 7,17 & 388,87 & 0,370 & $7.847,78$ \\
\hline
\end{tabular}

EV: Espaçamento vertical; DM: Declividade média; CT: Comprimento do terraço; AT: Altura do terraço; AI: Área de influência. 
dimensionada (Seção), a lâmina de escoamento superficial, vazão, tensão máxima e perda do solo no canal da estrada.

Caso a perda de solo excedesse a perda máxima considerada tolerável, conforme estabelecido no software, o relatório emitido apresentaria os resultados com mudança de cor no texto (de preto para vermelho), o que não foi observado em nenhum trecho. Caso o texto estivesse em vermelho, o intervalo medido entre terraços não poderia ser utilizado como espaçamento entre desaguadouros da estrada, devendo-se realizar adequações nos projetos. O relatório emitido pelo software Estradas indica, também, o volume escoado, o qual corresponde ao volume que, neste caso, deverá ser armazenado pelo terraço.

A partir dos volumes de escoamento superficial de cada trecho de estrada, foi possível calcular o incremento na altura do terraço. De modo geral, observou-se que, em média, os terraços tiveram aumento na altura recomendada de $3,06 \%$, o que corresponde a um aumento relativamente pequeno. Também, verificou-se que, quanto maior o comprimento do terraço menor o valor do incremento na altura, uma vez que o escoamento advindo da estrada será distribuído ao longo de um maior trecho de acumulação.

Em trechos com maior comprimento de estrada entre os terraços, como nos trechos $2 \mathrm{~A}$ e $2 \mathrm{D}$, consequentemente, o volume de escoamento superficial a ser armazenado foi maior, bem como o incremento na altura do terraço. Observou-se, porém, que os maiores trechos de estrada compreendidos entre terraços são encontrados quando o sentido da estrada se aproxima de uma situação de paralelismo, em relação ao terraço, ou seja, quanto mais em contorno estiver a estrada, maior será o trecho correspondente localizado entre os terraços.

A utilização dos terraços para armazenar o escoamento das estradas tem como benefício uma menor perda de área, uma vez que a área inutilizada para plantio seria a mesma, caso fossem implantados apenas os terraços para armazenar o escoamento da área agrícola. Na Tabela 2, encontram-se os valores de altura de projeto recomendada para os terraços de armazenamento, considerando-se apenas o escoamento da área agrícola (altura inicial) e os valores de altura recomendada para armazenamento da integração terraço-estrada (altura final), bem como valores percentuais de incremento na altura de cada terraço. Nota-se que os valores de altura recomendada foram
Tabela 2. Alturas recomendadas para os terraços, considerandose apenas o armazenamento do escoamento da área agrícola, a integração terraço-estrada e valores percentuais do incremento em altura.

\begin{tabular}{cccc}
\hline \multirow{2}{*}{ Terraço } & AI & AF & IA \\
\cline { 2 - 3 } & & $\mathrm{m}$ & $\%$ \\
\hline 1 & 0,298 & 0,364 & 22,50 \\
2 & 0,343 & 0,365 & 6,35 \\
3 & 0,353 & 0,366 & 3,79 \\
4 & 0,359 & 0,381 & 6,19 \\
5 & 0,355 & 0,362 & 1,87 \\
6 & 0,379 & 0,381 & 0,46 \\
7 & 0,370 & 0,373 & 0,76 \\
\hline
\end{tabular}

AI: Altura inicial; AF: Altura final; IA: Incremento em altura.

relativamente baixos, uma vez que esta é somente a altura de projeto, restando, ainda, calcular a altura, considerando-se um coeficiente de desuniformidade e uma margem de segurança ou bordadura. Ressalta-se, porém, que as dimensões das estradas e as características do escoamento podem alterar substancialmente estes valores.

Mesmo nos terraços em que o incremento apresentou os maiores valores percentuais, como nos terraços 1,2 e 4 , verificou-se que o incremento em altura foi relativamente pequeno, com $6,6 \mathrm{~cm}$, para o terraço 1 , e $2,2 \mathrm{~cm}$, para os terraços 2 e 4 . Apesar do pequeno incremento que se fez necessário, é importante ressaltar que se trata da altura de projeto, sem considerar uma margem de segurança e um coeficiente de desuniformidade. Ao calcular as alturas recomendadas, considerando-se a margem de segurança e o coeficiente de desuniformidade, pequenos incrementos na altura de projeto geram variações na altura calculada.

Em situações adversas, como trechos curtos de terraços, que, por sua vez, recebem um volume de escoamento superficial correspondente a um longo trecho de estrada, estes pontos de risco são verificados e dimensionados. Caso a integração fosse feita sem o devido dimensionamento, haveria grande risco de rompimento do terraço. Em Paraná (1994), por exemplo, ressaltou-se que uma das principais causas de rompimento dos terraços é a convergência, para estes, de águas advindas de estradas e carreadores, $\mathrm{o}$ que reforça a necessidade de um correto dimensionamento desta integração.

Embora utilize cálculos simples, a integração terraço-estrada, por meio de aplicativos computacionais, facilitaria sua execução e reduziria a chance de erros de cálculo. Além disto, a junção de parte dos 
processos envolvidos, utilizando-se os softwares Estradas e Terraço, ao aplicativo de integração terraço-estrada eliminaria a necessidade de utilização simultânea de mais de um software, o que poderia gerar dificuldades quanto à utilização e realização dos cálculos necessários à integração.

\section{CONCLUSÕES}

1. A metodologia apresentada permitiu determinar o incremento na altura recomendada dos terraços, para que estes possam armazenar não somente o escoamento superficial da área agrícola, mas, também, aquele proveniente de estradas rurais.

2. A utilização dos terraços para armazenamento do escoamento superficial das estradas é uma prática viável, com pequeno incremento na altura recomendada do terraço.

3. O método é de fácil execução, podendo ser aplicado em áreas agrícolas sem maiores complicações e possibilitando melhor utilização dos recursos disponíveis, além de apresentar grande potencial para uso na extensão rural.

4. A integração terraço-estrada, por meio de aplicativos computacionais, facilitaria sua execução e reduziria a chance de erros de cálculo.

\section{REFERÊNCIAS}

ASSOCIAÇAO BRASILEIRADENORMAS TÉCNICAS (ABNT). NBR 13133: execução de levantamento topográfico. Rio de Janeiro: ABNT, 1994.

COSTA, L. C. et al. Infiltração de água em solo, determinada por simulador de chuvas e pelo método dos anéis. Revista Brasileira de Engenharia Agrícola e Ambiental, Campina Grande, v. 3, n. 2, p. 131-134, 1999.

GRIEBELER, N. P. Modelo para o dimensionamento de redes de drenagem e de bacias de acumulação de água em estradas não pavimentadas. 2002. $134 \mathrm{f}$. Tese (Doutorado em Engenharia Agrícola)-Universidade Federal de Viçosa, Viçosa, 2002.

GRIEBELER, N. P. et al. Modelo para o dimensionamento e a locação de sistemas de terraceamento em nível. Engenharia Agrícola, Jaboticabal, v. 25, n. 3, p. 841851, 2005.

GRIEBELER, N. P. et al. Variabilidade espacial da seção transversal de terraços posicionados em nível. Engenharia na Agricultura, Viçosa, v. 6, n. 1, p. 1-11, 1998.

OLIVEIRA, J. M. Atenuação dos riscos em sistemas de terraceamento em Goiás. 2010. 84 f. Dissertação
(Mestrado em Agronomia)-Universidade Federal de Goiás, Goiânia, 2010.

OLIVEIRA, J. F. et al. Erodibilidade e tensão crítica de cisalhamento em solos de estradas não pavimentadas. Revista Brasileira de Engenharia Agrícola e Ambiental, Campina Grande, v. 13, supl., p. 955-960, 2009.

OLIVEIRA, L. F. C. et al. Intensidade-duração-frequência de chuvas para localidades no Estado de Goiás e Distrito Federal. Pesquisa Agropecuária Tropical, Goiânia, v. 35, n. 1, p. 13-18, 2005.

PARANÁ. Secretaria de Estado da Agricultura e do Abastecimento. Manual técnico do subprograma de manejo e conservação do solo. Curitiba: Secretaria de Estado da Agricultura e do Abastecimento, 1994.

PRUSKI, F. F. et al. HIDROS: dimensionamento de sistemas hidroagríolas. Viçosa: UFV, 2006. 